\title{
DC\#28995
}

QA:NA

O6/06/01

\section{Migration of water pulse through fractured porous media}

\author{
S. Finsterle $^{1 *}$, J. T. Fabryka-Martin ${ }^{2}$, and J. S. Y. Wang ${ }^{1}$ \\ ${ }^{1}$ Earth Sciences Division, Lawrence Berkeley National Laboratory, Berkeley, CA, USA \\ ${ }^{2}$ Los Alamos National Laboratory, Los Alamos, NM, USA
}

\begin{abstract}
Contaminant transport from waste-disposal sites is strongly affected by the presence of fractures and the degree of fracture-matrix interaction. Characterization of potential contaminant plumes at such sites is difficult, both experimentally and numerically. Simulations of water flow through fractured rock were performed to examine the penetration depth of a large pulse of water entering such a system. Construction water traced with lithium bromide was released during the excavation of a tunnel at Yucca Mountain, Nevada, which is located in an unsaturated fractured tuff formation. Modeling of construction-water migration is qualitatively compared with bromide-to-chloride $(\mathrm{Br} / \mathrm{Cl})$ ratio data for pore-water salts extracted from drillcores. The influences of local heterogeneities in the fracture network and variations in hydrogeologic parameters were examined by sensitivity analyses and Monte Carlo simulations. The simulation results are qualitatively consistent with the observed $\mathrm{Br} / \mathrm{Cl}$ signals, although these data may only indicate a minimum penetration depth, and water may have migrated further through the fracture network.
\end{abstract}

Keywords: Unsaturated zone; Fracture-matrix interaction; Dual permeability; Numerical modeling; Yucca Mountain

\footnotetext{
* Corresponding author: Fax: +1-510-486-5686; e-mail:SAFinsterle@lbl.gov
} 


\section{Introduction}

Contaminant transport from waste-disposal sites located above the groundwater table is strongly affected by the characteristics that affect water flowing through partially saturated discrete features (such as networks of fractures or macropores). Flow in unsaturated, heterogeneous fracture networks usually exhibits a complex pattern as a result of channeling, fingering, funneling, and bifurcation effects. Fast flow paths may be established, leading to rapid migration of solutes through the unsaturated zone (Nativ et al., 1995; Fabryka-Martin et al., 1997a). On the other hand, the interaction of contaminants with the rock matrix — by advective imbibition, diffusion, or adsorptionmay significantly increase travel times to the groundwater table. Additional effects related to film flow, flow through and along fracture coatings, diffusion into stagnant water, etc., further complicate characterization, prediction, and remediation of contaminated fractured formations.

Many of the mechanisms governing flow and transport in partially saturated fractured-porous media are described in Evans and Nicholson (1987), Bear et al. (1993), Sahimi (1995), and Pruess (1998, 1999). Various conceptual, analytical, and numerical models have been developed to address specific aspects of the problem (see, for example, Birkholzer and Tsang (1997) for unsaturated channeling effects, Tokunaga and Wan (1997) for film flow, Robinson et al. (1998) for analyses of fracture skin effects, and Pruess et al. (1999a) for a summary of alternative conceptual models). Studies considering the effects of a permeable matrix using dual- or multi-porosity models usually deal with saturated conditions (Barenblatt et al., 1960; Warren and Root, 1963; Rubin et al., 1999). Under partially saturated conditions, additional processes such as 
phase interference in the fractures (Persoff and Pruess, 1995), the reduced wetted fracture area available for fracture-matrix interaction (Liu et al., 1998), and matrix imbibition driven by capillary forces (Philip, 1957; Thoma et al., 1992) need to be considered.

Experimental determination of flow and transport in unsaturated fractured rock faces challenges that are intrinsic to the system behavior. Heterogeneities and the discreteness of the fractures are likely to lead to chaotic flow paths and thus erratic contaminant distributions (Pruess et al., 1999a, Faybishenko et al., 2000). Furthermore, fractures and matrix exhibit order-of-magnitude differences in properties and behavior (both in space and time), making it difficult to design measurement devices and monitoring systems that capture both aspects simultaneously (Finsterle and Faybishenko, 1999). This situation leads to the following two fundamental, opposing problems of data analysis. First, point measurements in fractured systems provide only a weak basis for estimating integral quantities (such as the distribution and total mass of contaminants), because the measurements usually do not represent average conditions. Secondly, intrinsic averaging occurring during the measurement process potentially obliterates key mechanisms (such as the fast transport of small contaminant quantities through the fracture network). Note that a similar problem exists in modeling when using effective continuum concepts to simulate transport in fractured-porous media.

This study is an illustration of the second problem described above. Concentration measurements were taken to estimate the penetration depth of a large pulse of traced water released into partially saturated, fractured tuff. The data were qualitatively reproduced using a heterogeneous dual-continuum model. Extensive sensitivity and Monte Carlo simulations were performed to examine the impact of parameter 
uncertainties and spatial variability on the calculated concentration distribution. The modeling demonstrates that the interpretation of the chemical signal is inconclusive, in that it can yield only an apparent penetration depth. Water is likely to migrate to greater depths through the network of interconnected fractures, a behavior not captured by the measured concentrations, which depend mainly on matrix imbibition effects.

The paper is organized as follows: Section 2 provides background information and describes the measured data. The modeling approach is discussed in Section 3, followed in Section 4 by a presentation of simulation results, including the sensitivity analyses. Section 5 contains a summary and discussion of the major results.

\section{Data Review}

The U.S. Department of Energy (DOE) is investigating the unsaturated zone at Yucca Mountain, Nevada, as a potential site for the disposal of spent fuel and high-level nuclear wastes. Within the geological formations at Yucca Mountain, which consist of alternating layers of welded and nonwelded ash flow and ash fall tuffs, the potential repository horizon lies in the Topopah Spring welded unit, featuring relatively low matrix permeability and high fracture density. Two subunits are of special interest to this study (see Buesch et al. (1996) for a detailed description and nomenclature of lithostratigraphic units at Yucca Mountain). The highly fractured middle nonlithophysal zone (Tptpmn) has an average fracture spacing of about $0.53 \mathrm{~m}$, a bulk permeability of about $7 \times 10^{-12} \mathrm{~m}^{2}$, and a matrix porosity of about $9 \%$. In contrast, the upper lithophysal zone (Tptpul) exhibits a lower degree of fracturing (average fracture spacing of $1.45 \mathrm{~m}$ ), but a higher matrix porosity $(14 \%)$, higher bulk permeability $\left(26 \times 10^{-12} \mathrm{~m}^{2}\right)$, and weaker capillarity 
than the underlying middle nonlithophysal zone. The fracture spacings indicated above were derived from fracture trace maps and appropriately corrected borehole data. They represent fractures of length $1 \mathrm{~m}$ or larger, i.e., they do not include smaller fractures and microfractures that are potentially important. The Tptpul contains lithophysal cavities, which resulted from vapor inclusions during cooling of magma.

To gain access for the characterization of the potential repository host rock, an $8 \mathrm{~km}$ long, $8 \mathrm{~m}$ diameter tunnel, the Exploratory Studies Facility (ESF), was excavated between 1994 and 1997. The amount of water used for the construction of the ESF is obviously a key factor affecting transport and migration depth. While the total water usage is measurable and reasonably well known, considerable uncertainty remains about the fraction of water that actually enters the formation. The fate of construction water in the ESF depends on its specific usage: It may be removed from the tunnel with the muck or by ventilation, or be imbibed into the formation. Water is used at the cutter head for emplacing rock bolts, washing walls, and controlling dust on the conveyer belt. The bulk of the construction water is removed from the system with the muck. Johnson and Kappes (1997) analyzed the average quantities of water used and removed from the tunnel for $200 \mathrm{~m}$ long sections. They estimated the average amount of unaccounted water to be $1,500 \pm 500$ liters per meter of tunnel. This amount will be assumed to be released into the fractured formation at the invert of the tunnel.

Approximately 6 months after the tunnel boring machine passed their respective locations, three slanted boreholes (named CWAT\#1, CWAT\#2, and CWAT\#3) were drilled downwards from the ESF. The locations of the boreholes along the ESF are shown in Figure 1. The chemistry of the pore-water salts extracted from the drillcores was 
analyzed in an attempt to track the migration of the construction water, providing information on water flow in the fractured, unsaturated tuffs at Yucca Mountain.

Construction water was traced with lithium bromide to a concentration of $20 \mathrm{ppm}$ bromide. The bromide-to-chloride $(\mathrm{Br} / \mathrm{Cl})$ ratio in this water was 2.9 , which is significantly higher than that in naturally percolating pore waters $(\leq 0.01)$ (FabrykaMartin et al., 1997b). Pore-water salts were extracted from CWAT drillcores by leaching about 100 grams of rock with an equal mass of deionized water for 48 hours. Samples were crushed into 1 to $2 \mathrm{~cm}$ size fragments prior to leaching. The leached solutions were then analyzed for chloride and bromide by ion chromatography.

The minimum $\mathrm{Br} / \mathrm{Cl}$ ratio indicating the presence of construction water in a sample was determined based on a statistical criterion. The $65 \mathrm{Br} / \mathrm{Cl}$ data points were ranked from lowest to highest, and the cumulative average and standard deviation for each step of the ranking was calculated. As each new data point was included in the cumulative average, the mean was subtracted from the highest-value data point, and the result was divided by the corresponding standard deviation. These ratios are plotted in Figure 2 as a function of ranking, with the solid line representing the Chauvenet's criterion for identifying outliers (Bevington and Robinson, 1992). Chauvenet's criterion states that a data point is considered an outlier of a Gaussian distribution if the probability of such a value being that far from the cumulative mean of the ranked data set is less than $0.5 \%$. Based on this statistical test, construction water is assumed to be present in a given porewater sample if its $\mathrm{Br} / \mathrm{Cl}$ ratio is greater than 0.01 .

The measured $\mathrm{Br} / \mathrm{Cl}$ ratio profiles are shown in Figure 3. The shallowest apparent penetration depth was found in borehole CWAT\#3, in which a construction water signal 
was detected only in the top 2 meters. The deepest penetration was in CWAT\#2, in which construction water had reached the bottom of the hole at approximately $-30 \mathrm{~m}$. In CWAT\#1, construction water was detected in all samples to a depth of $2.4 \mathrm{~m}$ and in two isolated peaks at depths of $6.7 \mathrm{~m}$ and $8.5 \mathrm{~m}$.

Differences in migration distances are most likely related to differences in water application rates and in hydraulic characteristics of the geologic units at each location. CWAT\#1 and CWAT\#2 are both located in the highly fractured middle nonlithophysal zone (Tptpmn) of the Topopah Spring welded tuff unit. Construction-water losses were likely highest at CWAT\#2, which is located near an alcove with underground activities that introduced additional amounts of traced water, notably about 10,000 liters from a water-line break discovered shortly before the hole was drilled. The more limited migration observed in CWAT\#3 is probably a result of the upper $5.2 \mathrm{~m}$ of this hole being located in the upper lithophysal zone (Tptpul), which has fewer fractures of length greater than $1 \mathrm{~m}$, but many microfractures promoting matrix imbibition. In addition, these fractures may terminate at lithophysal cavities, further increasing storage capacity in this unit. $\mathrm{Br} / \mathrm{Cl}$ ratios for the upper part of $\mathrm{CWAT} \# 3$ are significantly larger than those for the same interval in CWAT\#1, suggesting that a larger proportion of construction water may have been retained in the Tptpul matrix in CWAT\#3 as compared to the Tptpmn matrix in CWAT\#1. We used numerical modeling to further examine the hypotheses discussed above concerning the fate of the construction water and the associated $\mathrm{Br} / \mathrm{Cl}$ signal. 


\section{Model Development}

Although natural pore waters reside predominantly in the matrix, the very limited matrix permeability forces construction water to flow through the network of interconnected fractures. A fraction of the released water imbibes into the matrix, leaving behind a chemical construction water signal. In such a conceptual model, the abundance of fractures as well as the fracture network geometry are key factors affecting construction water migration and its chemical signature in the matrix pore water. The velocity with which a pulse of water propagates through the fractures determines the time available for matrix imbibition, which in turn determines the bromide concentration in the matrix pore water. In addition, flow velocity and residence times are strongly affected by local heterogeneities and the contact area between the fractures and the matrix. Individual peaks in the $\mathrm{Br} / \mathrm{Cl}$ ratio profile as shown in Figure 3 may be attributed to discontinuities in the fracture network, where the termination of a fracture leads to accumulation and increased imbibition of construction water at that location. Note, however, that variability in the $\mathrm{Br} / \mathrm{Cl}$ ratio is also related to the varying distances of sampling points from the nearest fracture. Core samples intersecting a fracture are likely to show higher concentrations than samples taken from the center of a matrix block, which can be reached only by means of relatively slow processes such as diffusion and capillary imbibition.

Given the conceptual model outlined here, the representation of fractures and the matrix in the model as well as the interaction between them are of critical importance. Moreover, heterogeneity in the fracture continuum is considered a relevant feature of the system and is thus incorporated in the model. 
We developed a two-dimensional, vertical model with the invert of the ESF at the upper boundary to simulate construction water migration. The model domain is rectangular with a vertical symmetry axis going through the center of the invert. To resolve the pressure and saturation gradients between the fractures and the matrix, we employed the method of "Multiple Interacting Continua" (MINC; Pruess and Narasimhan, 1982, 1985). The MINC concept is based on the notion that changes in matrix conditions are controlled by the distance from the fractures. In this approach, all fractures are combined into a single fracture continuum (Continuum 1), and all matrix material within a certain, relatively short distance from the fractures is combined into Continuum 2. Matrix material at increasingly larger distances becomes Continuum 3 and so forth. For the simulations presented here, the model domain was discretized into primary gridblocks of size $\Delta \mathrm{X} \times \Delta \mathrm{Y} \times \Delta \mathrm{Z}=0.3 \mathrm{~m} \times 1.0 \mathrm{~m} \times 0.3 \mathrm{~m}$. Each gridblock was then further subdivided into a total of four continua: one for the fracture continuum with a volume fraction equal to fracture porosity $\phi_{f}$, and three matrix continua with volume fractions of $0.05,0.20$, and $\left(0.75-\phi_{f}\right)$, respectively. Note that these volume fractions are chosen for numerical reasons only-they have no geological significance. All continua represented in a MINC model are interlaced and thus occupy the same physical space.

A heterogeneous permeability field was generated for the fracture continuum using Sequential Indicator Simulation (Deutsch and Journel, 1992). The simulation was based on the statistical parameters inferred from air-injection tests conducted in the middle nonlithophysal zone (CRWMS M\&O, 2000b). Spatial correlation of the log-permeability field follows a spherical semivariogram, with a nugget effect of 0.43 , a correlation length of $3.8 \mathrm{~m}$, and a sill value of 0.51 . The cumulative distribution function of log- 
permeability values was discretized from the distribution of the measured airpermeability data. One realization of the resulting log-permeability field is shown in Figure 4 . The three matrix continua are assumed to be homogeneous with respect to hydraulic parameters. The fracture permeability field exhibits both local obstacles in the fracture continuum as well as high-permeability channels. These obstacles may represent dead-end fractures, discontinuities in the fracture network, asperity contacts, or heterogeneity in the amount and properties of fracture fillings. Figure 4 and all the following figures involving fracture-matrix water-content comparisons show the fracture continuum on the left of the symmetry axis, and one of the three matrix continua on the right.

Unsaturated flow through both the fracture and matrix continua is described using Richards' equation (Richards, 1931), which is implemented in the integral finite difference simulator TOUGH2 (Pruess et al., 1999b):

$$
\frac{\partial}{\partial t} \phi S \rho=\operatorname{div}\left[k \frac{k_{r}}{\mu} \rho \nabla(P+\rho g z)\right]
$$

Here, $t$ is time, $\phi$ is porosity, $S$ is liquid saturation, $\rho$ is liquid density, $k$ is absolute permeability, $k_{r}$ is relative permeability, $\mu$ is viscosity, $g$ is gravitational acceleration, $z$ is the vertical coordinate (positive upward), and $P=P_{r e f}+P_{c}$ is liquid-phase pressure, where $P_{r e f}$ is a reference gas pressure and $P_{c}$ is capillary pressure. Relative permeability and capillary pressure are functions of liquid saturation as given by van Genuchten (1980):

$$
k_{r}=S_{e}^{1 / 2}\left[1-\left(1-S_{e}^{1 / m}\right)^{m}\right]^{p}
$$




$$
P_{c}=-\frac{1}{\alpha}\left[S_{e}^{-1 / m}-1\right]^{-m},
$$

where the effective saturation $S_{e}$ is defined as

$$
S_{e}=\frac{S-S_{l r}}{1-S_{l r}}
$$

In the van Genuchten model, $S_{l r}$ is residual liquid saturation, and $\alpha$ and $m$ are fitting parameters.

The spatial and temporal distribution of construction water release is unknown. For simplicity we assumed that the time period over which construction water is applied and released as the tunnel boring machine travels 1 meter, was on the order of 1 day, i.e., the release of construction water (1,500 liters per meter for the base-case scenario) was modeled as a 1-day pulse, uniformly applied over the invert of the ESF ( $|\mathrm{X}|<3 \mathrm{~m}$ in Figure 5). No-flow boundaries were specified at the symmetry axis $(X=0)$, at the outer vertical model boundary $(|X|=9 \mathrm{~m})$, and at the upper boundary $(3 \mathrm{~m}<|\mathrm{X}|<9 \mathrm{~m})$. To avoid capillary end effects, we specified a free drainage boundary condition at the bottom of the model domain at $Z=-40 \mathrm{~m}$. The initial water saturation in the fracture and matrix continua was set to be 0.01 and 0.93 , respectively. This corresponds to approximate capillary equilibrium between the fractures and the matrix for the base-case parameter set (see below). Given the large amount of construction water released, potential effects from a slight disequilibrium at initial conditions as well as from the small natural percolation flux can be neglected.

Boreholes CWAT\#1 and CWAT\#2 are located in the generally densely welded, highly fractured middle nonlithophysal zone of the Topopah Spring tuff unit. The upper $5.2 \mathrm{~m}$ of borehole CWAT\#3 is located in the less fractured, moderately to densely welded 
upper lithophysal zone of the Topopah Spring tuff unit, but for simulation purposes is was assumed to be Tptpul throughout the model domain. The hydrogeologic parameter values of both units (see Tables 1 and 2) were taken from the base-case parameter set of the site-scale unsaturated zone model of Yucca Mountain (CRWMS M\&O, 2000a). Some of these hydrogeologic parameters were determined by model calibration, assuming steady-state conditions with ambient percolation fluxes (Bandurraga and Bodvarsson, 1999). These fluxes are orders of magnitude lower than the amount of water released during tunnel construction, and both the spatial and temporal scales are significantly larger. Therefore, the model-related parameters determined for the simulation of ambient flows may not be appropriate for predicting vastly different flow scenarios (such as the migration of large amounts of construction water). Nevertheless, we base our simulations on the site-scale model parameter set to test how well it explains the general behavior of construction-water migration in a fractured porous medium.

\section{Simulation Results and Sensitivity Analyses}

In the following analysis, a change in water content, $\Delta \Theta=\phi\left(S-S_{0}\right)$, is assumed to represent a change in bromide concentration or $\mathrm{Br} / \mathrm{Cl}$ ratio. This assumption seems reasonable if the chemical composition of the water changes due to mixing of in-situ pore water and added construction water. An early-time increase in water content is evidently caused by imbibition of traced construction water, which makes water content changes indicative of average concentration changes within the gridblock. However, a decrease in water content at late times may not necessarily indicate a decrease in tracer concentration, but may simply reflect a reduction in the amount of traced water in that specific 
gridblock. Once construction water has entered the matrix, capillary pressure gradients and molecular diffusion lead to a redistribution and homogenization of the solutes within the matrix block. The relatively small diffusion coefficients for bromide $\left(2.03 \times 10^{-9} \mathrm{~m}^{2}\right.$ $\mathrm{s}^{-1}$ ) and chloride (Lasaga, 1998) prevent significant diffusive transport to occur for the time frame considered in this study; diffusion is therefore neglected. We further assume that the anions behave like conservative tracers and that the primary transport mechanisms leading to the observed construction-water signal are advection (predominantly through the fracture network) and matrix imbibition. Potential retardation of the tracer is neglected. Depending on the bromide and chloride concentrations in the construction water and the corresponding background values in the natural pore water, we can estimate that a water content increase of at least $0.2 \%$ is required to provide a clear indication of the presence of construction water.

Figure 5 shows the water-content changes in the fracture continuum (left) and in the volume-weighted average of all matrix continua (right) at times $1,10,30$, and 180 days after passage of the tunnel boring machine, for the Tptpmn case representing CWAT\#1 and CWAT\#2. The water content changes in the fracture continuum indicate that water flows rather quickly through the fracture network. Because of the relatively high fracture permeability, construction water infiltrates into the formation without ponding at the invert; this prediction is supported by field observations. The fracture network distributes water and gets it in contact with the partly desaturated matrix, into which it is imbibed by capillary forces. Water content changes in the fractures damp out with time and with depth as a result of downward migration and matrix imbibition. At the time of data collection, measured $\mathrm{Br} / \mathrm{Cl}$ values are dominated by and representative of matrix 
concentrations. Consequently, the efficiency of fracture-matrix interaction becomes the most important mechanism governing the distribution of the observable constructionwater signal.

Local reductions in fracture permeability lead to local subsurface ponding, which enables increased matrix imbibition. As a result, the water-content distribution in the (homogeneous) matrix reflects the heterogeneities of permeabilities in the fracture continuum, with higher water content increases occurring where the residence time for matrix imbibition is longer because of local ponding. Heterogeneity may also increase the horizontal spreading of the construction water. Local ponding, entrapment, and horizontal spreading reduce the overall velocity with which the bulk of the construction water migrates downwards. On the other hand, funneling effects may concentrate flow into channels, increasing the penetration depths at certain locations.

After 10 days (Figure $5 \mathrm{~b}$ ), the bulk of the construction water has already migrated to considerable depth through the Tptpmn fracture network, and approximately $65 \%$ of the released water has been imbibed into the adjacent matrix blocks. After 180 days (Figure 5d), the water pockets in the fracture continuum have largely disappeared as a result of matrix imbibition and gravitational downward flow. The water content distribution in the matrix is smoothed out. Nevertheless, the pattern of variable construction water uptake is preserved, most likely leading to a nonuniform bromide distribution profile (despite homogeneous matrix properties).

The imbibition process is further illustrated in Figure 6, which shows the change in water content in the second continuum-the matrix immediately adjacent to the fractures - and third continuum after 1 day and 180 days. Recall that the second 
continuum comprises $5 \%$ of the rock volume and is located closer to the fractures (approximately $0.006 \mathrm{~m}$ ) than the third continuum, which encompasses $20 \%$ of the matrix at an average distance of approximately $0.02 \mathrm{~m}$ from the fractures. Figures $5 \mathrm{a}$ and $6 \mathrm{a}$ combined illustrate the early-time gradient in water content from the fractures to the center matrix block across the four continua, which provides the capillary driving force for imbibition. Figures $5 \mathrm{~d}$ and $6 \mathrm{~b}$ show that redistribution within the Tptpmn matrix is close to being complete after 180 days, which is approximately when the CWAT holes were drilled.

To evaluate the impact of fracture heterogeneity on matrix imbibition, we generated 50 realizations of the Tptpmn permeability field with identical geostatistical properties. Figure 7 shows the total amount of water imbibed into the three matrix continua between the elevation of the ESF and a depth of $30 \mathrm{~m}$ as a function of time for all realizations. A histogram of the amount of water imbibed into the Tptpmn matrix after 1 year is shown on the right panel of Figure 7 . The variability in calculated matrix imbibition is relatively large given that all hydrogeologic and geostatistical parameters are identical; the only difference between individual realizations is a spatial rearrangement of fracture permeabilities. The difference between the amount imbibed and the amount applied (1500 liters) is the volume of water predicted to have been migrated to depths greater than $30 \mathrm{~m}$.

The left panel of Figure 7 also reveals that approximately two thirds of matrix imbibition is complete after about 10 days, which is the time during which the construction water travels to depths greater than $30 \mathrm{~m}$ through the fracture network. After that, drainage and imbibition of construction water continues at a slower pace. Once 
water is imbibed into the matrix, the matrix permeability is too low for a visible vertical displacement of the construction-water signal within the time frame considered here. Consequently, after about 10 days, the exact time at which the boreholes were drilled and samples were taken is of little consequence regarding the exact vertical position of the plume.

Having evaluated the impact of spatial variability, we next assessed the uncertainty of the model predictions given uncertainty in the input parameters. First, a sensitivity analysis was performed to evaluate the relative importance of the parameters listed in Table 3. (From an inverse perspective, the sensitivity coefficients can also be interpreted as the amount of information contained in the data, if evaluated along the profile where borehole measurements were made). Each parameter was changed from its base-case value by a certain amount, $\delta$ (the same value is used as the input standard deviation for the Monte Carlo simulations of parameter variability). A composite, dimensionless sensitivity measure $\Omega_{j}$ for parameter $p_{j}$ was then defined as follows:

$$
\Omega_{j}=\sum_{k=1}^{n_{k}} \sum_{i=1}^{m}\left|\phi_{k} v_{k} \cdot \frac{\Delta S_{i}\left(\mathbf{p}+\delta_{j} \mathbf{e}_{j}\right)-\Delta S_{i}\left(\mathbf{p}-\delta_{j} \mathbf{e}_{j}\right)}{2 \delta_{j}} \cdot \frac{\delta_{j}}{\sigma_{i}}\right|
$$

Here, $\mathbf{p}$ is the base-case parameter vector, $\mathbf{e}_{j}$ is the $j$ th column of the identity matrix, $\Delta S_{i}$ is the saturation change in gridblock $i, i=1, \ldots, m$ after 180 days, where $m$ is the number of gridblocks along the borehole, $\phi_{k}$ and $v_{k}$ are the porosity and volume fraction of continuum $k$, respectively, $n_{k}=4$ is the number of continua, and $\sigma_{i}$ is a scaling factor (here arbitrarily set to 1.0 ). Despite the subjectivity of the chosen weighting factors $\delta_{j}$, the sensitivity analysis confirms that the calculated water content changes and thus 
the observed $\mathrm{Br} / \mathrm{Cl}$ ratios are predominantly affected by the matrix sorptivity, and-to a lesser extent— the diffusivity of the fracture system. Matrix porosity $\phi_{m}$ turns out to be the most sensitive parameter (albeit not significantly), because a higher porosity provides additional pore space for water imbibition, directly affecting the maximum and thus actual water-content change. Note that even the large uncertainty in the released amount of construction water has a smaller impact on predicted water-content changes than a moderate uncertainty in matrix properties. The results further indicate that the measured $\mathrm{Br} / \mathrm{Cl}$ data contain little information about the Tptpmn fracture properties, even though the fractures largely determine the construction-water migration distance. The relative sensitivity of field data to the fracture properties would be higher immediately after construction-water release (i.e., fracture properties could be inferred if accurate earlytime measurements were available).

To examine the impact of parameter uncertainty on the model predictions, we performed 50 Monte Carlo simulations, in which parameter values were sampled from uncorrelated normal distributions with the standard deviations indicated in the third column of Table 3 . Figure 8 shows the resulting profiles of water content changes (volume averaged over all 4 continua) after 180 days along the centerline at $X=0$. The profile obtained with the base-case parameter set is shown as a dotted line; the average profile from all 50 realizations is represented by the thick solid line. Predicted profiles vary considerably. If the construction-water release rate is high and locally saturates the fracture network, an almost vertical curve is obtained in the upper part of the profile, the change being equal to the difference between the initial and fully saturated water content for the prevailing value of matrix porosity. A similar behavior is also observed if the 
random parameter set favors matrix imbibition (i.e., high matrix permeability combined with strong capillarity). If less water is released or matrix sorptivity is relatively weak, saturation changes and thus unsaturated hydraulic properties are more accentuated, leading to high-amplitude fluctuations. Since all curves are based on the same fracture permeability pattern, the location of major peaks is similar in all realizations.

Figure 9 shows the combined effect of parameter uncertainty and stochastic variability in the Tptpmn heterogeneous fracture-permeability field. The average profile of all resulting water-content curves (thick line) is rather smooth and tends to decrease with depth. However, individual realizations show a random pattern of relatively high amplitude (note that only the first 25 Monte Carlo realizations are plotted). Many of the realizations qualitatively match the characteristics of the observed $\mathrm{Br} / \mathrm{Cl}$ ratio profile in borehole CWAT\#2 (see Figure 3). Specifically, sharp gradients in the profile and the occurrence of isolated construction-water signals at depth are evident. This behavior is not captured by the average curve, for which one might have falsely concluded that the construction-water signal propagates in a diffusive, monotonically decreasing manner.

Finally, we performed a construction-water release simulation using properties believed to be representative for the upper lithophysal zone (Tptpul, see Table 2). The resulting average profile is plotted in Figure 10, showing water-content changes that are smaller compared to those in the middle nonlithophysal zone (Tptpmn). In fact, the calculated water-content changes are near or below the approximate construction-water detection limit of $0.2 \%$. This behavior is qualitatively consistent with the absence of detectable deep construction water signals in borehole CWAT\#3 (see Figure 3). The simulation suggests, however, that construction water migrates to considerable depths, 
mainly because the Tptpul unit exhibits higher fracture permeability and lower fracture porosity. Moreover, the hydrogeologic properties suggest that the potential for matrix imbibition could be smaller. The sorptivities $s$ of the two units are very similar, assuming the approximate relationship $s \propto \sqrt{k / \alpha}$ (Zimmerman and Bodvarsson, 1991). However, while the matrix sorptivity determines imbibition from a single fracture, the larger spacing of fractures carrying the construction-water pulse through the Tptpul ( $1.23 \mathrm{~m}$ versus $0.23 \mathrm{~m}$ in the Tptpmn; see Tables 2 and 1) significantly reduces the overall area available for fracture-matrix interaction. This reduced interaction area and the larger matrix block volume lead to smaller water content increases in the matrix, resulting in an apparent absence of construction water in the simulations.

This interpretation is based on simulation results only; it is believed to be correct for hydrogeologic units with the idealized properties summarized in Tables 1 and 2 . However, there may be other explanations for the absence of a construction-water signal below a depth of $2 \mathrm{~m}$ in CWAT\#3 (see Figure 3). For example, construction-water loss at this location may have been significantly lower compared to that near borehole CWAT\#2, where considerable amounts of construction water were used for the excavation of a nearby alcove and were released in a water-line break. Also note that the fracture spacing reported for Tptpul in Table 2 was derived from fracture-trace maps that exclude small fractures and microfractures. Small fractures are generally abundant in the lithophysal units. If interconnected and if not bypassed by the water pulse traveling through the high-permeability network of larger fractures, these small fractures may provide access to and sufficient surface area for increased matrix imbibition. Given the relatively larger storage potential (higher matrix porosity, lower initial saturation, 
lithophysal cavities), all the released construction water may be held in the formation immediately below the excavated tunnel without significant vertical migration. The shallow front with high $\mathrm{Br} / \mathrm{Cl}$ ratios in the top two meters of CWAT\#3 (see Figure 3) supports this hypothesis.

\section{Discussion and Conclusions}

The simulation results and the comparison between the behavior in two fractured units with different hydrogeologic properties (specifically fracture spacing) reveal that water-content changes and associated $\mathrm{Br} / \mathrm{Cl}$ ratios are representative of matrix conditions and are thus not necessarily indicative of the actual construction-water penetration depth. For example, using the hydrologic parameter set from Table 2, migration in the upper lithophysal zone is expected to be faster and to extend to greater depths because of the higher permeability, lower fracture porosity, and smaller amount of water being imbibed into the matrix. Since water that quickly flows through the fracture network does not leave a prominent $\mathrm{Br} / \mathrm{Cl}$ ratio signal, the apparent absence of significant increases in measured $\mathrm{Br} / \mathrm{Cl}$ ratios at certain locations along the profile may be misleading. More likely, however, the parameter set is not representative of the Tptpul hydrologic behavior, particularly because it neglects the role of microfractures in enhancing water imbibition.

We conclude that the observed $\mathrm{Br} / \mathrm{Cl}$ ratios provide an estimate of the minimum (rather than average or maximum) vertical distance to which the construction water pulse migrated through the densely welded fractured tuff. $\mathrm{The} \mathrm{Br} / \mathrm{Cl}$ signal gives an indication of the strength of matrix imbibition, which is affected by the residence times of water in the adjacent fractures and the matrix sorptivity properties. Small average permeability as 
well as local permeability reductions in the heterogeneous fracture network leads to increased matrix imbibition, which controls bromide accumulation and the final $\mathrm{Br} / \mathrm{Cl}$ distribution in the otherwise homogeneous matrix. As a result, the water content and chemical profiles beneath the ESF exhibit many local maxima and minima, as seen in the data (Figure 3) as well as in the simulations (Figures 8 and 9).

The measured profiles can be reproduced with many different parameter combinations and realizations of the underlying property fields. That is, the corresponding inverse problem is ill-posed, limiting the possibility of inferring hydrogeologic properties from matching $\mathrm{Br} / \mathrm{Cl}$ data. Moreover, predictions of $\mathrm{Br} / \mathrm{Cl}$ ratios are highly uncertain (see Figures 8 and 9) because channeling and ponding effects are almost impossible to predict deterministically. This difficulty results from a lack of information about fracture-network geometry and the spatial distribution of fracture hydraulic properties. Focusing on the average behavior of a discrete, highly variable and nonlinear system may lead to a misinterpretation of its key features, specifically the potential for fast and deep migration of water along preferential flow paths.

Nevertheless, the Tptpmn simulations discussed here yielded results that (1) are consistent with the observed range of $\mathrm{Br} / \mathrm{Cl}$ signals, and that (2) qualitatively reproduce the observed variability along a vertical profile. The apparent inconsistency of observing longer migration distances in a formation of lower permeability (Tptpul) (1) can either be explained as a result of reduced matrix imbibition due to larger fracture spacing, or (2) suggests the need to re-evaluate the hydrogeologic parameters for this unit.

The simulation results and conclusions presented in this study pertain to very large water pulses applied over short periods of time. They do not necessarily explain the 
behavior of the fractured-porous system at Yucca Mountain under natural, lowpercolation-flux conditions. However, construction-water migration studies from local pulse releases at drift inverts may help us understand the variabilities associated with future liquid releases of potentially contaminated water at sites located in fractured rocks. 
Acknowledgment Thanks are due to A. Flint, C. Doughty, B. Faybishenko, and E. Sonnenthal for their critical comments and suggestions for improvement. This work was supported by the Director, Office of Civilian Radioactive Waste Management, U.S. Department of Energy, through Memorandum Purchase Order EA9013MC5X between TRW Environmental Safety Systems and the Ernest Orlando Lawrence Berkeley National Laboratory (Berkeley Lab). The support is provided to Berkeley Lab through the U.S. Department of Energy Contract No. DE-AC03-76SF00098. 


\section{References}

Bandurraga, T.M, Bodvarsson, G.S., 1999. Calibrating hydrogeologic parameters for the 3-D site-scale unsaturated zone model of Yucca Mountain, Nevada. J. Contam. Hydrol. 38(1-3), 25-46.

Barenblatt, G.I., Zheltov, P.I., Kochina, N., 1960. Basic concept in the theory of seepage of homogeneous liquids in fissured rocks. J. Appl. Math. 24(5), 1286-1303.

Bear, J., Tsang, C.-F., deMarsily, G. (Eds.), 1993. Flow and Contaminant Transport in Fractured Rock. Academic Press, San Diego, Calif.

Bevington, P.R., Robinson, D.K., 1992. Data Reduction and Error Analysis for the Physical Sciences. McGraw Hill, New York, New York.

Birkholzer, J., Tsang, C.-F., 1997. Solute channeling in unsaturated heterogeneous porous media. Water Resour. Res. 33(10), 2221-2238.

Buesch, D.C., Spengler, R.W., Moyer, T.C., Geslin, J.K., 1996. Proposed Stratigraphic Nomenclature and Macroscopic Identification of Lithostratigraphic Units of the Paintbrush Group Exposed at Yucca Mountain, Nevada. U.S. Geol. Surv. Open File Report 94-469, Denver, Colorado.

CRWMS M\&O, 2000a. Calibrated Properties Model. Analysis/Model Report MDLNBS-HS-000003, ACC: MOL.19990720.0520 URN-0053, Civilian Radioactive Waste Management System, Management and Operating Contractor, Las Vegas, Nevada.

CRWMS M\&O, 2000b. Seepage Calibration Model and Seepage Testing Data. Analysis/Model Report MDL-NBS-HS-000004, Rev. 00, ACC: 
MOL.19990721.0521, Civilian Radioactive Waste Management System, Management and Operating Contractor, Las Vegas, Nevada.

Deutsch, C.V., Journel, A.G., 1992. GSLIB - Geostatistical Software Library and User's Guide. Oxford University Press, New York, New York.

Evans, D.D., Nicholson, T.J., 1987. Flow and Transport through Unsaturated Fractured Rock. American Geophysical Union Monograph No. 42, Washington, DC.

Fabryka-Martin, J.T., Wolfsberg, A.V., Dixon, P.R., Levy, S.S., Musgrave, J.A., Turin, H.J., 1997a. Summary Report of Chlorine-36 Studies: Sampling, Analysis and Simulation of Chlorine-36 in the Exploratory Studies Facility. Rep. LA-13352-MS, Los Alamos National Laboratory, Los Alamos, New Mexico.

Fabryka-Martin, J.T., Flint, A.L., Sweetkind, D.S., Wolfsberg, A.V., Levy, S.S., Roach, J.L., Woldegabriel, G., Wolfsberg, L.E., 1997b. Evaluation of Flow and Transport Models of Yucca Mountain, Based on Chlorine-36 Studies for FY-97. Rep. LACST-TIP-97-010, Los Alamos Natl. Lab., Los Alamos, New Mexico.

Faybishenko, B., Doughty, C., Steiger, M., Long, J.C.S., Wood, T.R., Jacobsen, J.S., Lore, J., Zawislanski, P.T., 2000. Conceptual model of the geometry and physics of water flow in a fractured basalt vadose zone, Water Resour. Res. 36(12), 3499-3520.

Finsterle, S., Faybishenko, B., 1999. What does a tensiometer measure in fractured rock?, in: Proceedings of the International Workshop on Characterization and Measurement of the Hydraulic Properties of Unsaturated Porous Media, edited by M.T. van Genuchten, J.J. Leiij, and L. Wu, 867-875, U.S. Salinity Lab., Riverside, California. 
Johnson, R.L., Kappes, J.A., 1997. Tracers, Fluids, and Materials Report, Yucca Mountain Site Characterization Project. Approval Document BAB000000-017172200-00005, Rev. 06, Reference No. KPB970908.06, Kiewit/PB.

Lasaga, A.C. 1998, Kinetic Theory in the Earth Sciences, Princeton University Press, Princeton, New Jersey.

Liu, H.H., Doughty, C., Bodvarsson, G.S., 1998. An active fracture model for unsaturated flow and transport in fractured rocks. Water Resour. Res. 34(10), 2633-2646.

Nativ, R., Adar, E., Dahan, O., Geyh, M., 1995. Water recharge and solute transport through the vadose zone of fractured chalk under desert conditions. Water Resour. Res. 31(2), 253-261.

Persoff, P., Pruess, K., 1995. Two-phase flow visualization and relative permeability measurement in natural rough-walled rock fractures. Water Resour. Res. 31(5), $1175-1186$.

Philip, J.R., 1957. The theory of infiltration: 4. Sorptivity and algebraic infiltration equations. Soil Sci. 84, 257-264.

Pruess, K., 1998. On water seepage and fast preferential flow in heterogeneous, unsaturated rock fractures. J. Contam. Hydrol. 30, 333-362.

Pruess, K., 1999. A mechanistic model for water seepage through thick unsaturated zones in fractured rocks of low matrix permeability. Water Resour. Res. 35(4), 1039-1051.

Pruess, K., Narasimhan, T.N., 1982. On fluid reserves and the production of superheated steam from fractured, vapor-dominated geothermal reservoirs. J. Geophys. Res. 87(B11), 9329-9339. 
Pruess, K., Narasimhan, T.N., 1985. A practical method for modeling fluid and heat flow in fractured porous media. Soc. Pet. Eng. J. 25(1), 14-26.

Pruess, K., Faybishenko, B., Bodvarsson, G.S., 1999a. Alternative concepts and approaches for modeling flow and transport in thick unsaturated zones of fractured rocks. J. Contam. Hydrol. 38, 281-322.

Pruess, K., Oldenburg, K., Moridis, G.J., 1999b. TOUGH2 User's Guide, Version 2.0, Report LBNL-43134, Lawrence Berkeley National Laboratory, Berkeley, Calif.

Richards, L. H., 1931. Capillary conduction of liquids through porous mediums. Physics, $1,318-333$.

Robinson, N.I., Sharp, J.M., Kreisel, I., 1998. Contaminant transport in sets of parallel finite fractures with fracture skins. J. Contam. Hydrol. 31, 83-109.

Rubin, H., Jansen, D., Forkel, C., Köngeter, J., 1999. Simulation of contaminant transport in fractured permeable formations by multiporosity modeling. J. Hydrol. 223, 107130.

Sahimi, M., 1995. Flow and Transport in Porous Media and Fractured Rock: From Classical Methods to Modern Approaches. VCH, Weinheim, Germany.

Thoma, S.G., Gallos, D.P., Smith, D.M., 1992. Impact of fracture coatings on fracture/matrix flow interactions in unsaturated, porous media. Water Resour. Res. 28(5), 1357-1367.

Tokunaga, T.K., Wan, J., 1997. Water film flow along fracture surfaces of porous rocks. Water Resour. Res. 33(6), 1287-1295. 
van Genuchten, M. T., 1980. A closed-form equation for predicting the hydraulic conductivity of unsaturated soils. Soil Sci. Soc. Am. J., 44, 892-898.

Warren, J.E., Root, P.J., 1963. The behavior of naturally fractured reservoirs. Soc. Pet. Eng. J. 3(5), 245-255.

Zimmerman, R.W., G.S. Bodvarsson, 1991. A simple approximate solution for horizontal infiltration in a Brooks-Corey medium, Transport in Porous Media, 6, 195-205. 
Table 1. Parameter Set of the Middle Nonlithophysal (Tptpmn) Zone

\begin{tabular}{lll}
\hline Parameter & Fracture & Matrix \\
\hline Permeability $k\left[\mathrm{~m}^{2}\right]$ & $2.76 \times 10^{-13 *}$ & $4.07 \times 10^{-18}$ \\
Porosity $\phi$ & $1.00 \times 10^{-2}$ & 0.11 \\
Fracture spacing $[\mathrm{m}]$ & 0.23 & - \\
van Genuchten $\alpha\left[\mathrm{Pa}^{-1}\right]$ & $5.16 \times 10^{-4}$ & $3.86 \times 10^{-6}$ \\
van Genuchten $m$ & 0.61 & 0.29 \\
Residual liquid saturation & 0.01 & 0.19 \\
$S_{l r}$ & & 0.93 \\
Initial liquid saturation & & \\
\hline Gigure 4. & 0.01 & \\
\hline
\end{tabular}


Table 2. Parameter Set of the Upper Lithophysal (Tptpul) Zone

\begin{tabular}{llc}
\hline Parameter & Fracture & Matrix \\
\hline Permeability $k\left[\mathrm{~m}^{2}\right]$ & $5.50 \times 10^{-13 *}$ & $3.08 \times 10^{-17}$ \\
Porosity $\phi$ & $6.60 \times 10^{-3}$ & 0.15 \\
Fracture spacing $\left[\mathrm{m}^{-3}\right]$ & 1.23 & - \\
van Genuchten $\alpha\left[\mathrm{Pa}^{-1}\right]$ & $1.46 \times 10^{-3}$ & $2.13 \times 10^{-5}$ \\
van Genuchten $m$ & 0.61 & 0.30 \\
Residual liquid saturation & 0.01 & 0.12 \\
$S_{l r}$ & & 0.78 \\
Initial liquid saturation & & \\
\hline Geometric mean of the heterogeneous log-permeability field. \\
\hline
\end{tabular}


Table 3. Tptpmn Parameters Varied During Sensitivity Analysis and Monte Carlo Simulations: Base-Case Value, Perturbation, and Composite Sensitivity Measure

\begin{tabular}{|c|c|c|c|}
\hline Parameter & $\begin{array}{l}\text { Base-case value } \\
\text { (from Table 1) }\end{array}$ & $\begin{array}{c}\text { Perturbation } \delta, \\
\text { Uncertainty }\end{array}$ & $\begin{array}{c}\text { Sensitivity } \Omega, \\
\text { Eq. (5) }\end{array}$ \\
\hline Water release $\left[\mathrm{kg} \mathrm{day}^{-1} \mathrm{~m}^{-1}\right]$ & 1500.0 & 500.00 & 0.75 \\
\hline $\log \left(k_{f}\left[\mathrm{~m}^{2}\right]\right)$ & -12.6 & 0.25 & 0.73 \\
\hline $\log \left(k_{m}\left[\mathrm{~m}^{2}\right]\right)$ & -17.4 & 0.25 & 0.77 \\
\hline $\log \left(\phi_{f}\right)$ & -2.0 & 0.25 & 0.17 \\
\hline $\log \left(\phi_{m}\right)$ & -1.0 & 0.10 & 1.22 \\
\hline $\log \left(\alpha_{f}\left[\mathrm{~Pa}^{-1}\right]\right)$ & -3.3 & 0.25 & 0.43 \\
\hline $\log \left(\alpha_{m}\left[\mathrm{~Pa}^{-1}\right]\right)$ & -5.4 & 0.25 & 0.82 \\
\hline
\end{tabular}




\section{Figure Captions}

Fig. 1. Location of CWAT boreholes along Exploratory Studies Facility and at Yucca Mountain, Nevada. Stratigraphic units are indicated using the nomenclature of Buesch et al. (1996).

Fig. 2. Application of Chauvenet's criterion to establish the cutoff $\mathrm{Br} / \mathrm{Cl}$ ratio for identifying the presence of traced construction water in leached CWAT drillcore samples.

Fig. 3. $\mathrm{Br} / \mathrm{Cl}$ profiles for salts leached from $\mathrm{CWAT}$ cores.

Fig. 4. One realization of the heterogeneous permeability field for the fracture continuum; the matrix is homogeneous. The model is symmetric about the line $X=0$. While both the fracture and matrix continua occupy the entire model domain, the fracture continuum is shown on the left and the matrix on the right of the symmetry axis.

Fig. 5. Volume-weighted average water-content changes in fracture continuum and matrix continuum (a) 1 day, (b) 10 days, (c) 30 days, and (d) 180 days after construction water release from the ESF invert in the middle nonlithophysal zone.

Fig. 6. Water-content changes in second and third matrix continua (a) 1 day and (b) 180 days after construction-water release from the ESF invert in the middle nonlithophysal zone. 
Fig. 7. Amount of water imbibed into the matrix to a depth of $30 \mathrm{~m}$ below the construction water release point as a function of time are shown on the left for 50 geostatistically equivalent realizations of the fracture permeability field. The solid line represents the mean. The histogram of the final amount of matrix imbibition is shown on the right.

Fig. 8. Water-content change profiles along centerline calculated for the base-case parameter set (dashed line) and for multiple Monte Carlo realizations, reflecting the prediction uncertainty as a result of uncertainty in the input parameters. The average profile is shown by the thick line.

Fig. 9. Water-content change profiles along centerline calculated for the base-case parameter set (dashed line) and for multiple Monte Carlo realizations, reflecting the prediction uncertainty as a result of uncertainty in the input parameters and variability in the fracture continuum's permeability field. The average profile is shown by the thick line.

Fig. 10. Average water-content change profiles for construction-water release in the upper lithophysal zone (CWAT\#3) and the middle nonlithophysal zone (CWAT\#2). Triangles represent measurement locations in boreholes CWAT\#2 and CWAT\#3; filled triangles indicate detection of construction water. Detection limit is a water-content change of approximately $0.2 \%$. 


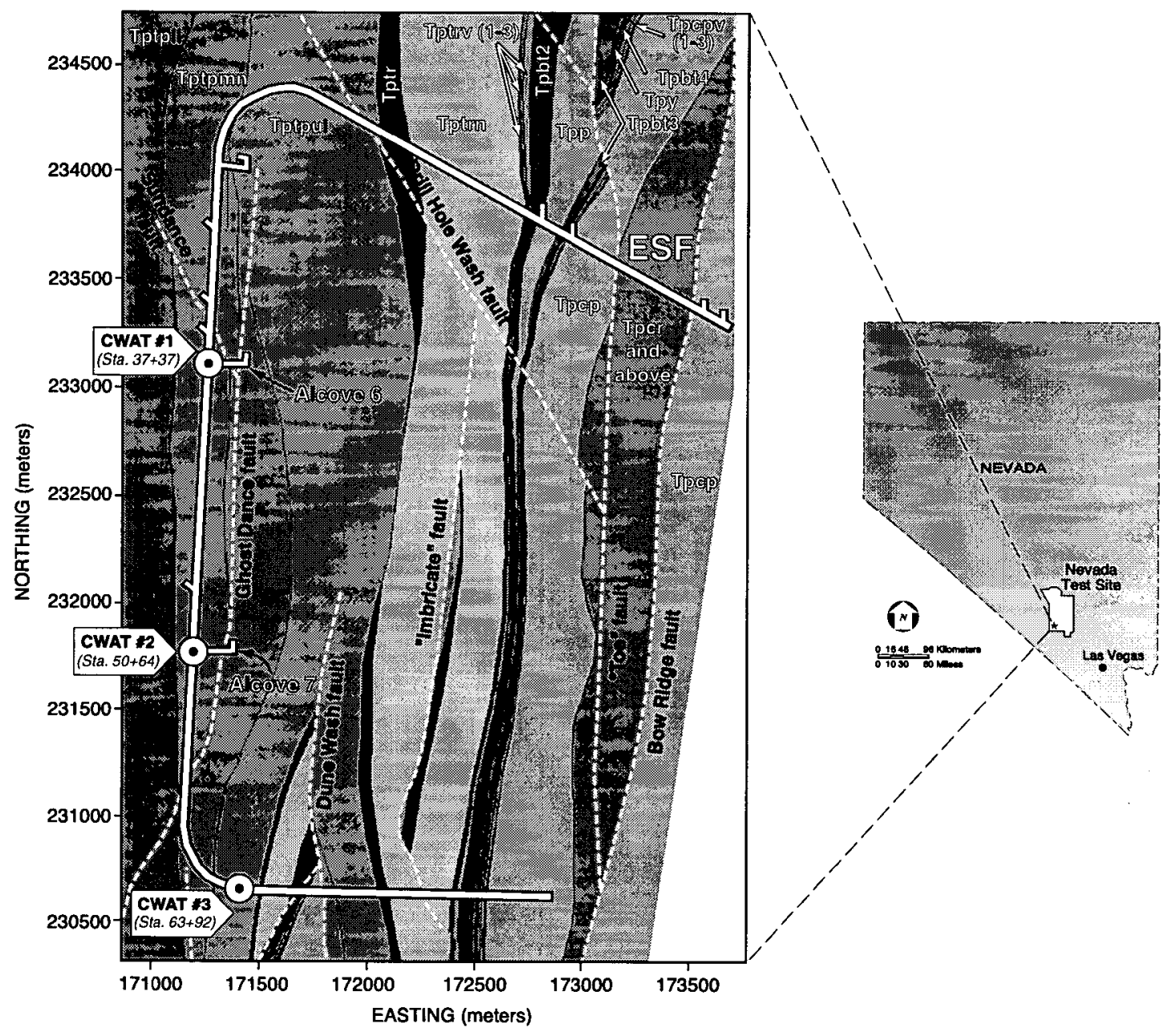

Fig. 1. Location of CWAT boreholes along Exploratory Studies Facility and at Yucca Mountain, Nevada. Stratigraphic units are indicated using the nomenclature of Buesch et al. (1996). 


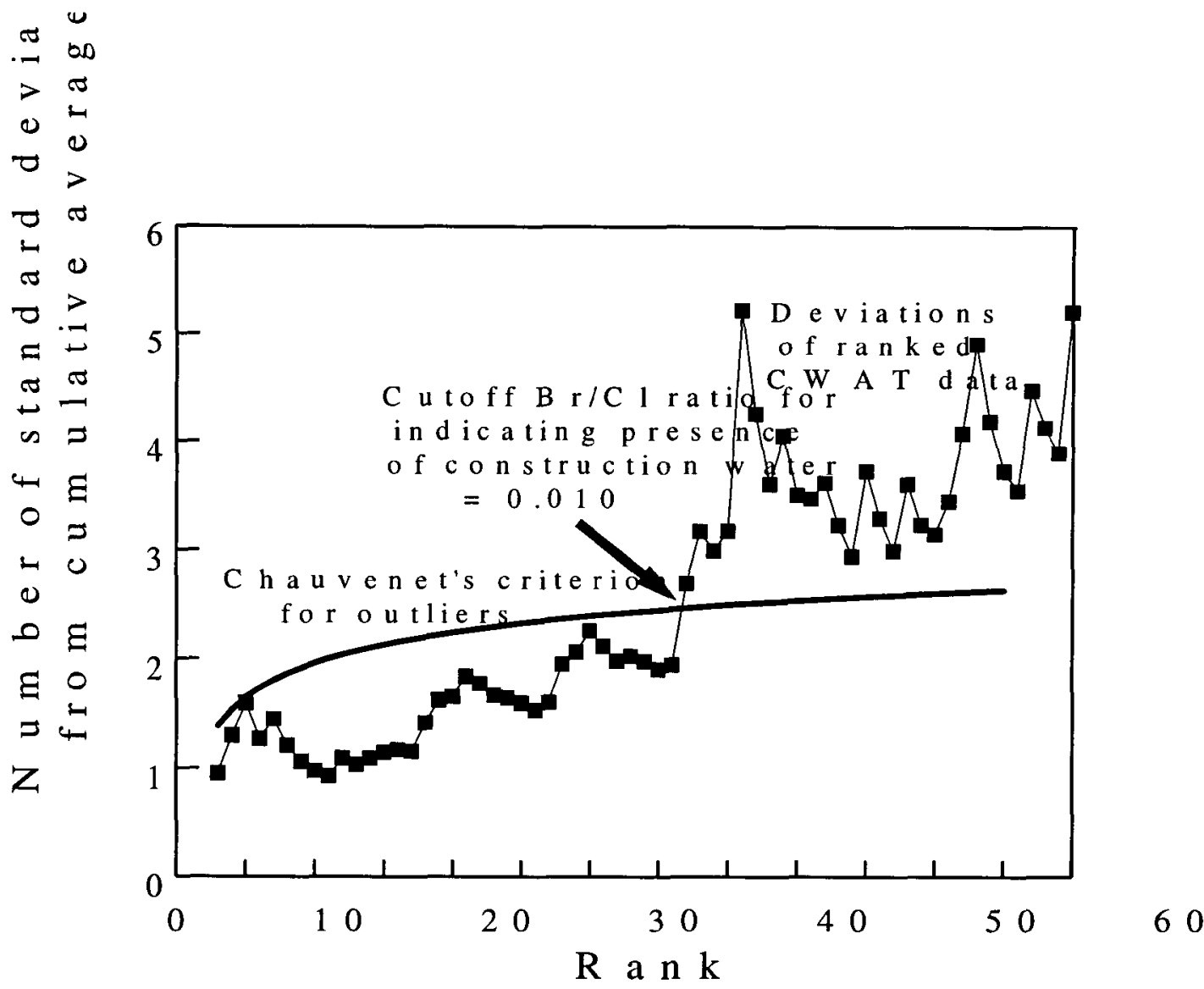

Fig. 2. Application of Chauvenet's criterion to establish the cutoff $\mathrm{Br} / \mathrm{Cl}$ ratio for identifying the presence of traced construction water in leached CWAT drillcore samples. 

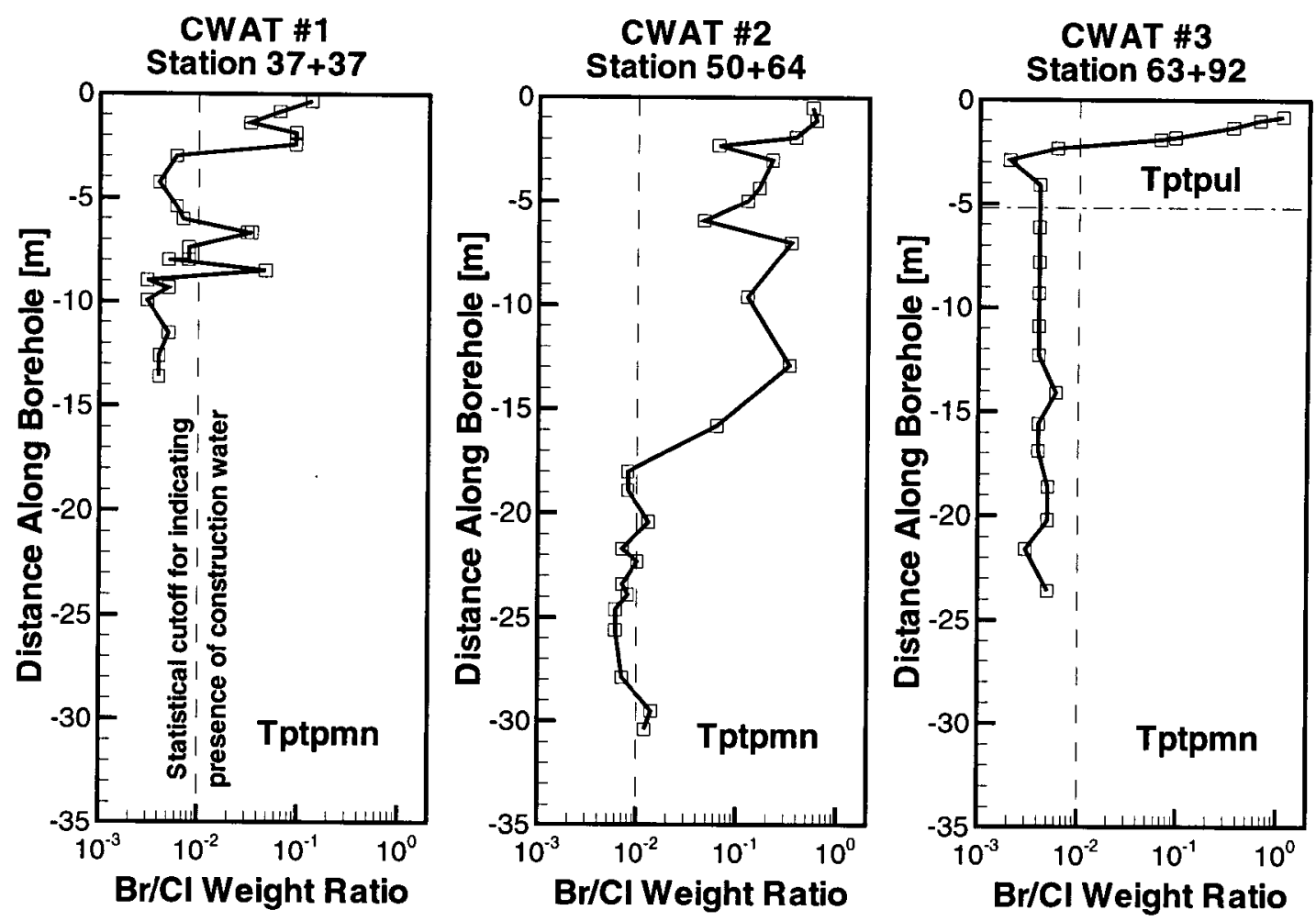

Fig. 3. $\mathrm{Br} / \mathrm{Cl}$ profiles for salts leached from CWAT cores. 


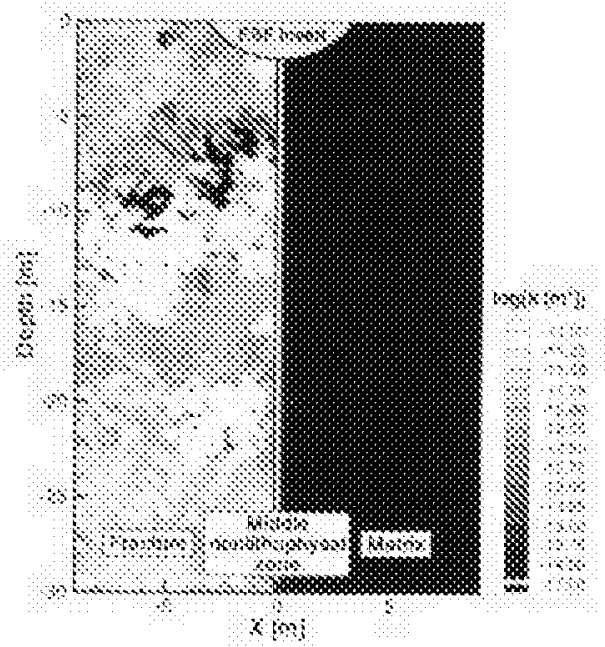

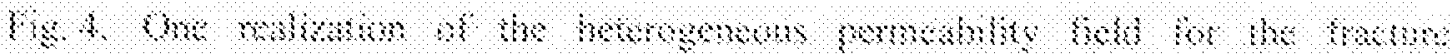

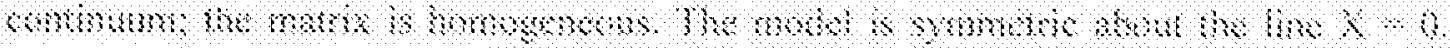

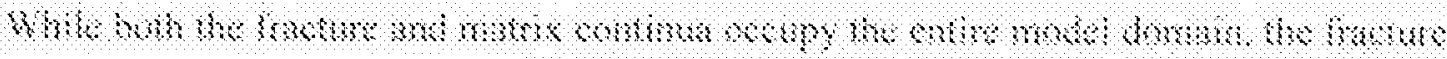

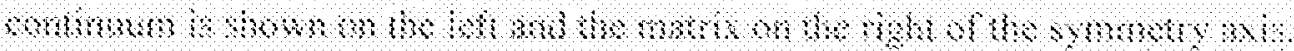




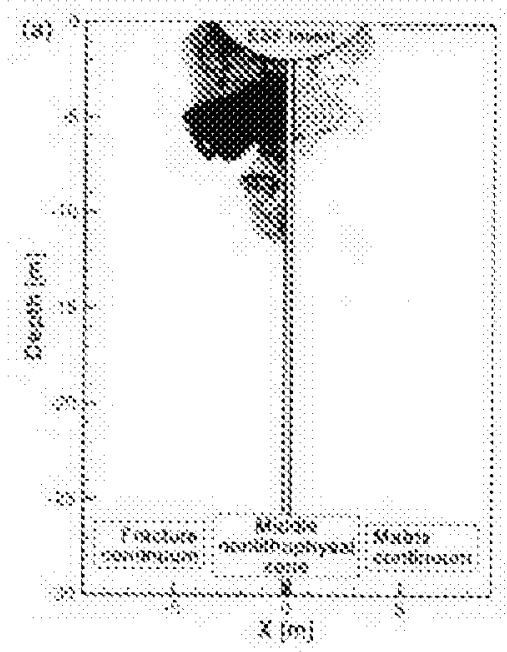

as
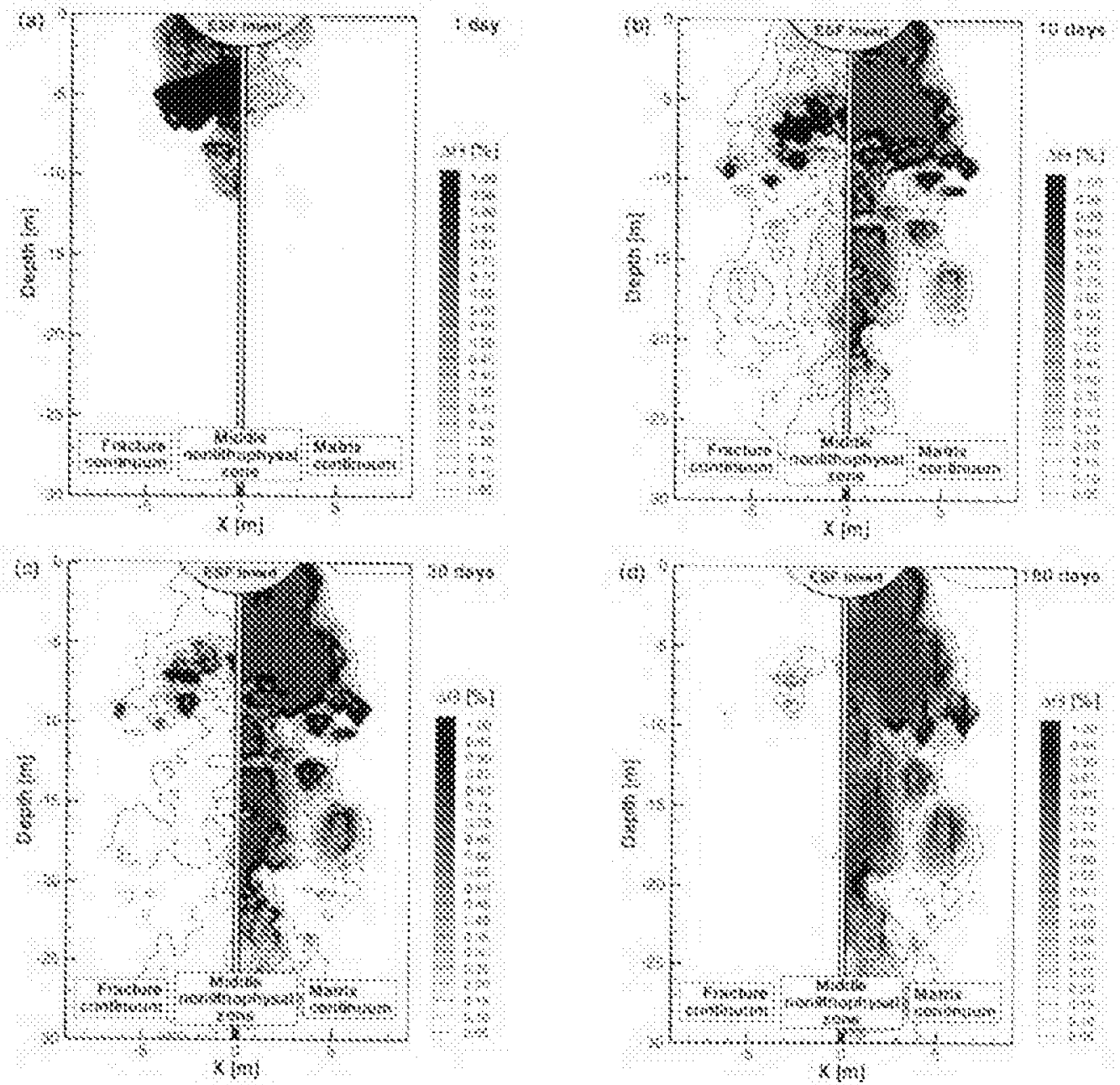

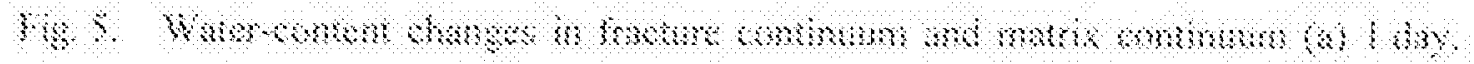

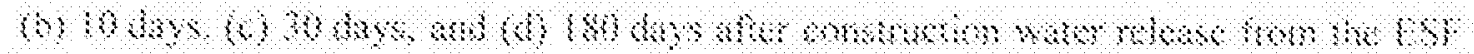

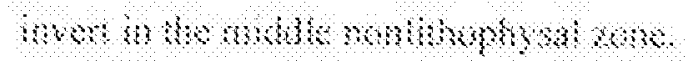



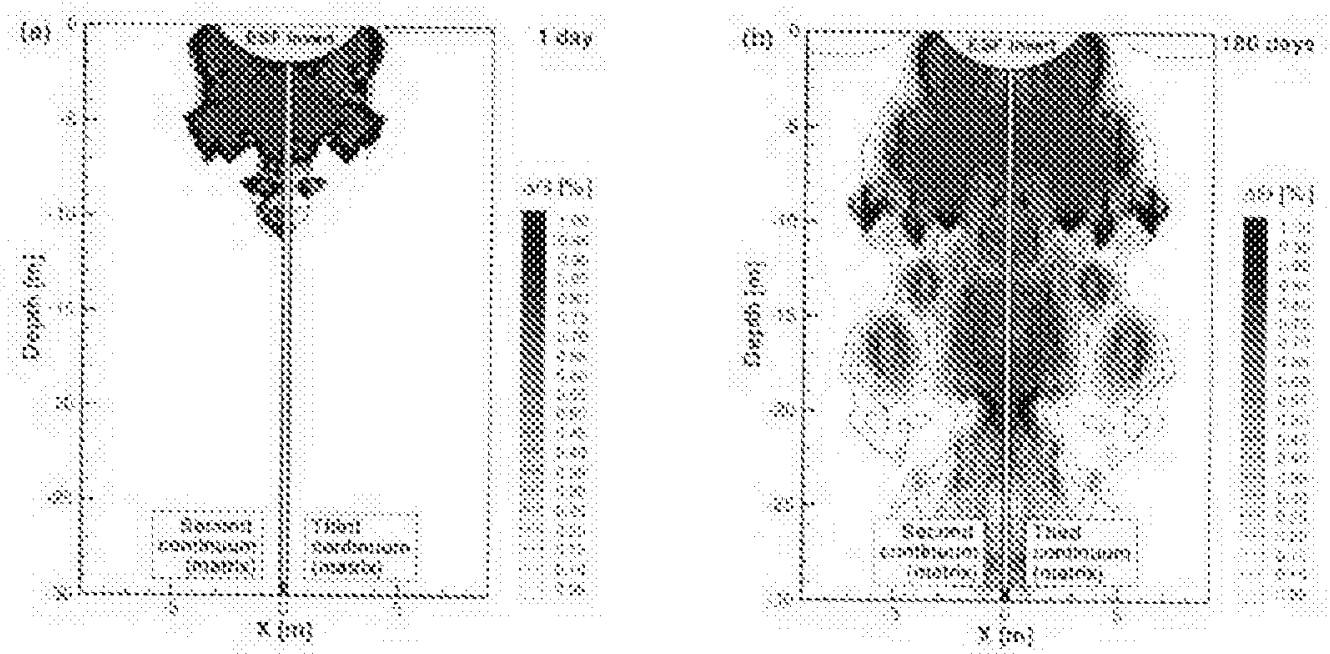

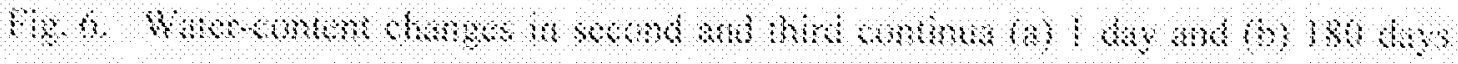

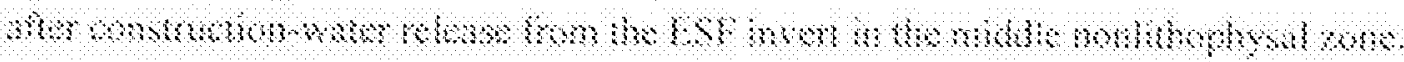




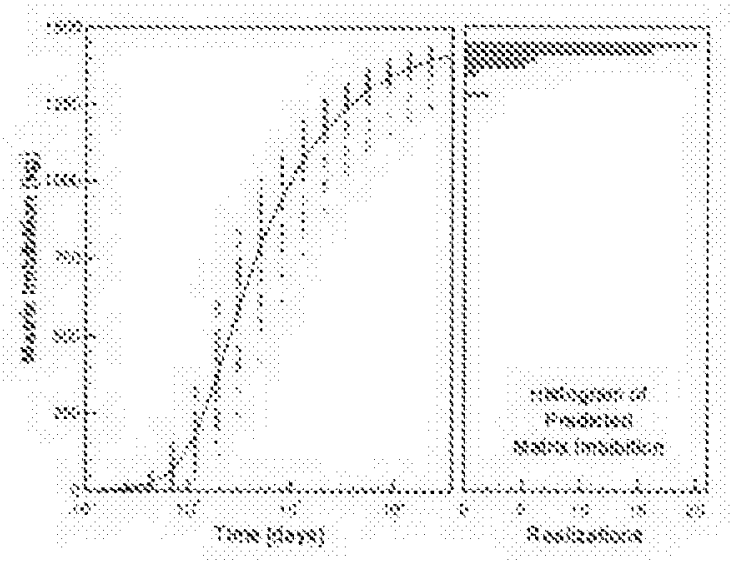

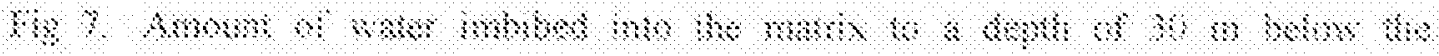

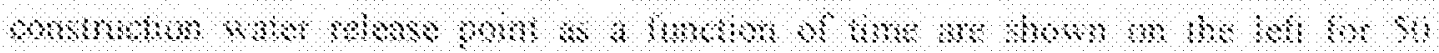

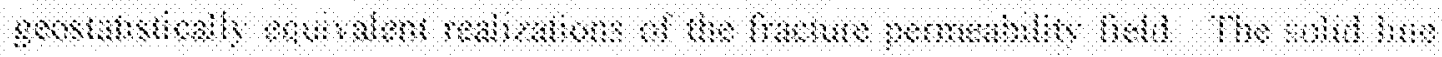

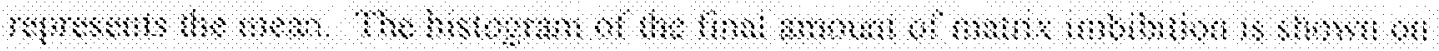
hersms. 


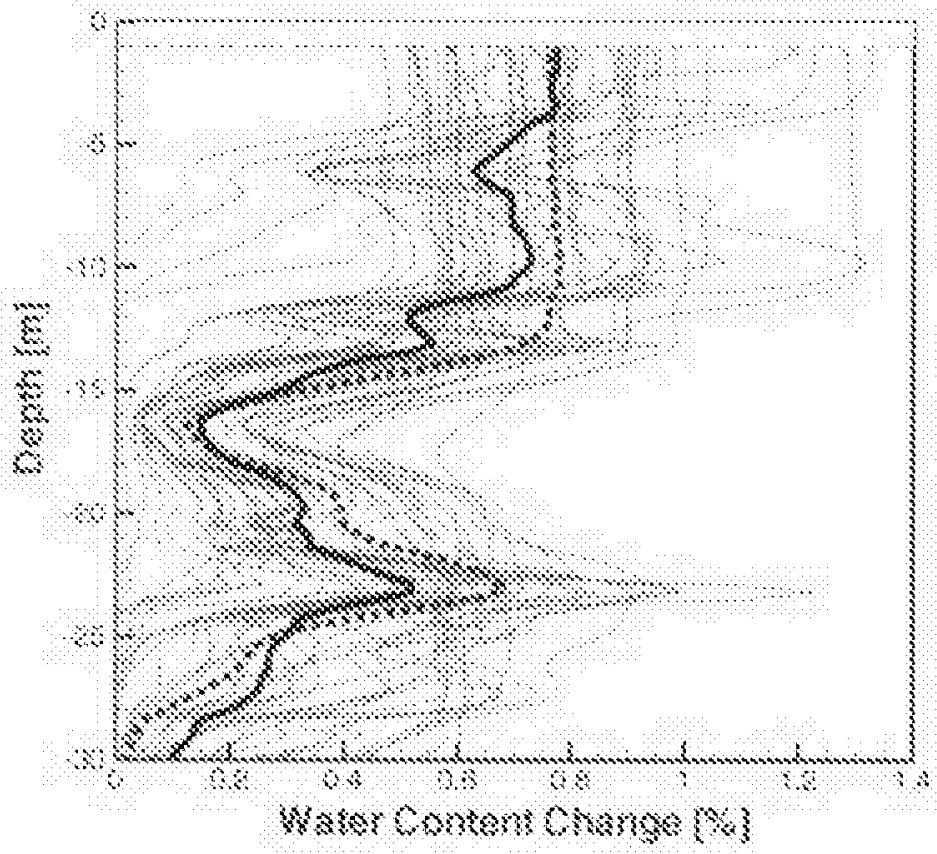

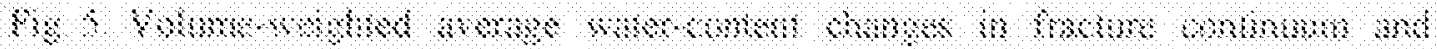

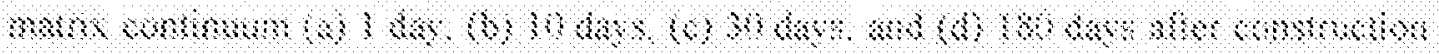

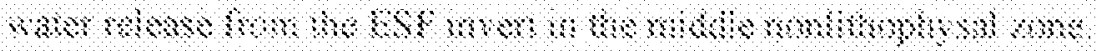




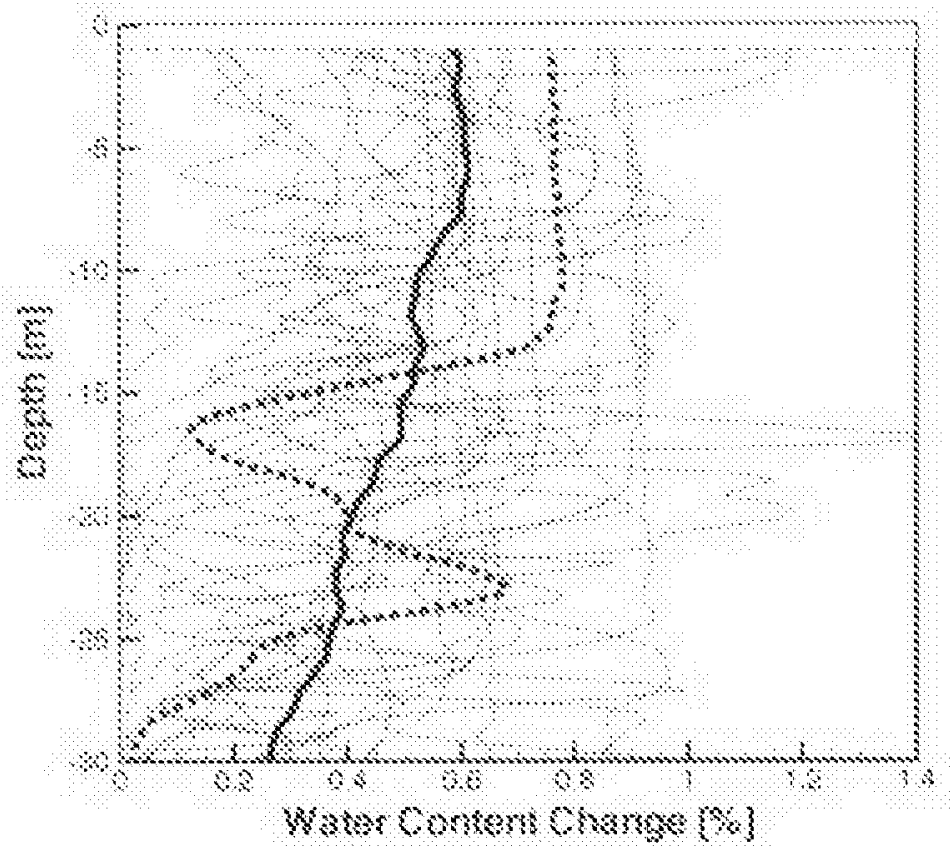

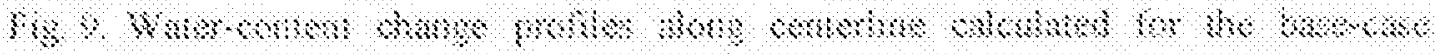

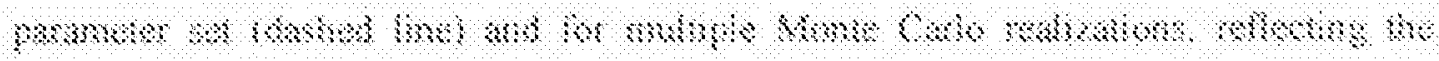

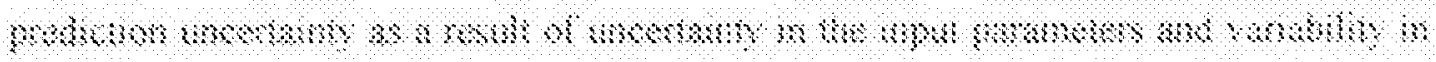

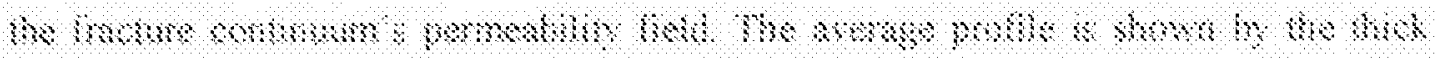
Wo 


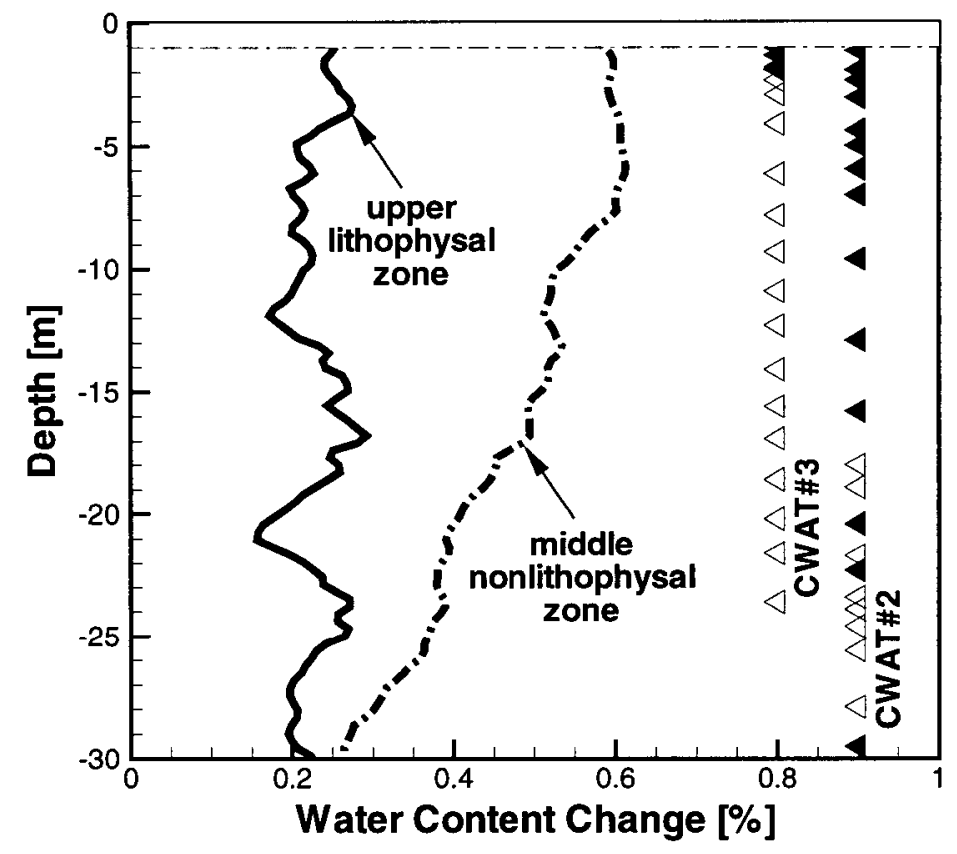

Fig. 10. Average water-content change profiles for construction-water release in the upper lithophysal zone (CWAT\#3) and the middle nonlithophysal zone (CWAT\#2). Triangles represent measurement locations in boreholes CWAT\#2 and CWAT\#3; filled triangles indicate detection of construction water. Detection limit is a water-content change of approximately $0.2 \%$. 